\title{
EL CARÁCTER INTEGRADOR DEL PENSAMIENTO \\ DE MORIN EN LA FORMACIÓN UNIVERSITARIA
}

\section{The integrator character of the Morin's thought in university formation}

\author{
FREDDY VARONA DOMINGGUEZ \\ Universidad de La Habana, La Habana, Cuba \\ fvarona@cepes.uh.cu \\ Código Orcid: https://orcid.org/0000-0002-5214-2735
}

\begin{abstract}
Resumen
Este estudio teórico se despliega en dos ámbitos. Uno de ellos es el de las ideas de una figura cimera del pensamiento complejo, Edgar Morin, de quien se revela algunas de sus consideraciones en torno a la integración, las cuales están mayormente implícitas en sus meditaciones. El otro ámbito es la formación universitaria, a propósito de la cual se reflexiona acerca del pensamiento complejo y de la eliminación de características que atentan contra el carácter integrador de la misma. Los objetivos de este trabajo son: argumentar el carácter integrador del pensamiento de Morin, y criticar las acciones que reducen el carácter integrador propio de la formación universitaria. La metodología empleada es la Documental, consistente en el estudio crítico de textos y el análisis de información escrita. Algunos de los resultados son: la revelación del carácter integrador de las ideas de Morin, la formulación de una definición de la categoría académica formación, y la crítica a la reducción del carácter integrador consustancial a la formación universitaria. Entre las conclusiones están: el carácter integrador del pensamiento de Morin tiene una base objetiva; el rasgo distintivo de la formación académica es que se realiza desde la conciencia del implicado y la atención a la afectividad en la formación universitaria fortalece su carácter integrador.
\end{abstract}

Pensamiento complejo, integración, formación, universidad, razón, afectividad.

Forma sugerida de citar: Varona, Freddy (2020). El carácter integrador del pensamiento de Morin en la formación universitaria. Sophia, colección de Filosofía de la Educación, 29, pp. 93-125.

* Doctor en Ciencias Filosóficas. Es profesor e investigador del Centro de Estudios para el Perfeccionamiento de la Educación Superior (CEPES) de la Universidad de La Habana. Una de sus líneas de investigación actuales es El pensamiento complejo y la transdisciplinariedad en el universo filosófico del siglo XXI: Repercusión en la educación superior, de ella tiene publicados artículos y ha presentado ponencias en eventos científicos nacionales e internacionales. 


\begin{abstract}
This theoretical study is deployed in two areas. One of them is that of the ideas of a leading figure of thought complex, Edgar Morin, from whom he reveals some of his considerations regarding integration, which are mostly implicit in his meditations. The other area is the university formation. Whit regard to it reflects on complex thinking and the elimination of characteristics that temp against its integrating character. The objectives of this work are: to argue the integrative character of Morin's thought and to criticize the actions that reduce the integrative character of the university formation. The methodology used is Documentary, consisting of the critical study of texts and the analysis of written information. Some of the results are: the revelation of the integrating character of Morin's ideas, the formulation of a definition of the academic category formation, and the critic of the reduction of the inherent integrative character of university formation. Among the conclusions are: the integrative character of Morin's thought has an objective basis; The distinctive feature of academic formation is that it is carried out from the conscience of the person involved and attention to affectivity in university formation strengthens its integrative character.
\end{abstract}

Keywords

Complex thinking, integration, formation, university, reason, affectivity

\title{
Introducción
}

Uno de los autores más estudiados durante los últimos años del siglo XX y los primeros del XXI es Edgar Morin, sociólogo y filósofo francés nacido en París en 1921; autor de una voluminosa obra escrita, tiene un sitio prominente en el pensamiento complejo, con el cual contribuye a conformar su esencia, establece gran parte de su base y principios y da consistencia a muchos de sus conceptos, o los perfila. Su gran lucha ha estado guiada por el propósito de lograr que la humanidad piense de un modo que religue y articule (esto no significa que niegue la modalidad de pensamiento que fragmenta y separa); tal objetivo condiciona que en el sustrato de sus ideas haya un espíritu integrador, no siempre explícito en sus consideraciones.

Ese tipo de pensamiento, denominado complejo, desde la penúltima década del siglo pasado ha atrapado la atención de muchos estudiosos de diferentes especialidades y ya tiene una numerosa lista de autores y una bibliografía profusa. Años antes la palabra complejidad había comenzado a variar su uso, que ya era amplio, debido a que tiene varias acepciones, pues con ella se alude cuanto se compone de elementos diversos, así como lo que es complicado, difícil, enmarañado, pero también los conjuntos o uniones de dos o más cosas, desde donde toman consistencia otros significados. A partir de la primera acepción y a lo largo de la segunda mitad de la vigésima centuria, dicha palabra pasó a asociarse a un grupo de ciencias que tienen, entre otras características, la orientación a las dinámicas no lineales y de autoorganización; a las mismas se empezó 
a denominar 'ciencias de la complejidad'. Pero la ampliación de la utilización del término de referencia, a su vez, se debió a que con él se empezó a nombrar a un tipo de enfoque de investigación (según el cual el interés investigativo se desarrolla desde las mencionadas especialidades nuevas) y a esta modalidad de pensamiento marcadamente filosófico, que se apoya en gran medida en dichos conocimientos científicos. De tal suerte, empezaron a cobrar relevancia (o a incrementarla) los sistemas abiertos, la multiplicidad de perspectivas, la autonomía, el valor de lo afectivo para la actividad científica y, entre muchos asuntos más, la oposición a los fraccionamientos forzados y a los reduccionismos.

Es en esa trama teórica que se mueve el pensamiento de Edgar Morin, sostenido e impulsado, ante todo, por su interés de sembrar en la humanidad la propensión a pensar mediante relaciones y a dejar a un lado la disyunción y el reduccionismo. Sobre esta base se erige el espíritu integrador, mayormente no explícito, que permea sus ideas y que es una de las causas de la atención tan grande que han despertado sus escritos. Dicho espíritu constituye el núcleo de la primera parte del presente trabajo, donde se devela su existencia inmersa en diversas elaboraciones teóricas en torno a los conocimientos científicos, la cultura, el futuro de la humanidad, la moral, la educación, temas estos universales y permanentes en el paso del tiempo.

La naturaleza integradora que irriga al pensamiento de Morin está, de una u otra forma en toda su obra escrita, que es grande, formada por una considerable cantidad de libros, artículos y otros textos, también numerosos; de ella, para este trabajo, se seleccionaron solo El Método, constituido por seis tomos, y Los siete saberes necesarios para la educación del futuro. Esta selección se debe a que en los mismos el espíritu integrador de sus ideas, casi siempre implícito en ellas, brinda grandes posibilidades para pensar y explayar elaboraciones teóricas, además, en ellos hay consideraciones sustanciosas que convidan a reflexionar acerca de la sociedad contemporánea y su futuro, así como en torno a la formación universitaria, cuya valía social es creciente

La revelación del espíritu integrador del pensamiento de Edgar Morin no en en sí lo más valioso de este trabajo, sino que en su develación se destaca la importancia que poseen para la vida humana de los tiempos actuales y de los por venir, pues el desarrollo de la humanidad exige cambiar el modo de pensar fraccionador, disyuntivo y abrirle el camino a una modalidad integradora, que ha de ser notorio en toda la sociedad y la cultura, de donde no es ajena la universidad, ni la labor formadora que tiene lugar en ella. 
A ese tema, el de la formación universitaria, se le dedica la segunda parte del presente trabajo, donde, al inicio, se exponen algunas consideraciones en torno a la categoría 'formación', tema polémico y necesitado de una mayor atención de los estudiosos de estos asuntos y de otros afines; esta exposición le abre paso al desarrollo de ideas acerca de la formación universitaria, que se aborda desde la perspectiva del pensamiento complejo y apoyado en el gran desarrollo actual de la ciencia y la tecnología,

Así se destaca que, a inicios de la tercera década del siglo XXI, en medio de progresos acelerados, transformaciones profundas y creaciones hasta hace poco tiempo impensables, aumentan las exigencias hacia la formación de los profesionales universitarios, quienes pueden ser mejores especialistas si se forman con una visión integradora; sin embargo, no siempre es así, pues el fraccionamiento y el reduccionismo todavía se hacen sentir en ella de varias maneras. Por tal razón, es necesario redoblar la atención hacia el carácter integrador que ha de sostenerla e impulsarla.

Tal intención tiene una marcada importancia no solo para el presente, sino también para el futuro, y no exclusivamente para la alta casa de estudios y sus egresados, pues, a su vez, es valioso para la sociedad en pleno, ya que se ataca el carácter disyuntivo y reduccionista que todavía está presente en la formación universitaria, rasgo contrario a la tendencia al fortalecimiento de un modo de pensar que religa e integra, que es el que exige la sociedad actual a partir del desarrollo de la ciencia y la tecnología y sus grandes avances posteriores, ya presumibles. Dicha insuficiencia se deja observar, entre otras modalidades posibles, en la sobrevaloración de lo laboral y el sobredimensionamiento de lo racional, causante de la segregación de lo afectivo y su anulación. Ambos casos son, en sentido estricto, manifestaciones de fraccionamiento y, más aún, de reduccionismo. Una de las grandezas de la universidad es la amplitud y variedad de la formación que se recibe en ella, aunque se despliegue alrededor de determinados propósitos cognoscitivos, encaminados a la realización de funciones sociales específicas. Impedir que la formación universitaria se estreche, es contribuir a su optimización y a la supervivencia de la diversidad humana.

Sobre esa base se desarrolla el presente trabajo, encaminado a contribuir a la solución del siguiente problema científico: ¿Qué significación tiene la esencia integradora de las ideas de Morin para combatir la reducción del carácter integrador de la formación universitaria? De tal suerte, la idea a defender es que el carácter integrador de las ideas de Morin ofrece argumentos básicos para luchar contra el reduccionismo y la disyunción en la formación universitaria. En correspondencia, este texto tiene dos objetivos, uno es revelar el carácter integrador del pensamiento de 
Morin a través de algunas de las consideraciones recogidas en sus obras El Método y Los siete saberes necesarios para la educación del futuro; el otro es criticar el espíritu reduccionista en la formación universitaria. La metodología empleada es la documental, consistente en el estudio crítico de textos y el análisis de información escrita, mediante la cual se conjugan presente-pasado-futuro. La bibliografía utilizada es variada; una parte considerable es de reciente publicación.

\section{Hallazgo del carácter integrador en las ideas de Morin}

Una de las obras más importantes de Edgar Morin es El Método (2002), en la cual expone desarrollos teóricos que trascienden el momento histórico cuando fueron escritos, y esto sucede porque, como asegura el autor Botto (2018), pueden utilizarse para explicar rasgos de la sociedad actual. En El Método, Morin muestra las insuficiencias del pensamiento mecanicista, lineal y determinista (propio del paradigma científico clásico, el cual ha prevalecido en las ciencias desde el siglo XVII) y lo hace apoyado en el desarrollo de la ciencia, a través del cual evidencia que el fraccionamiento y la disyunción consustanciales a dicho modo de pensar, no son suficientes para aprehender en su justa medida la complejidad de la vida actual. Es, como asegura la autora Calvo Cereijo (2019), la humanidad está "ante una ciencia que sale de las situaciones simples, ante un estudio de los procesos humanos que crecen en complejidad" (p. 324).

Morin (2002) destaca las separaciones que la humanidad ha construido durante siglos y enfatiza la necesidad de tomar conciencia al respecto y de revertir tal situación; para ello propone variar el modo de pensar: que no sea solo desde un ángulo, ni de una manera simplificadora, sino desde múltiples perspectivas, de un modo que se capte la complejidad de la vida. Muchas ideas suyas son valiosas cuando se emplean como lente en la realización de estudios. Así se han utilizado en diversas especialidades, respecto a lo cual pueden ponerse muchos ejemplos: terapia ocupacional, psicología, ciencias políticas, geografía, pedagogía, así lo muestran autores como Bellido Mainar (2016), Campero (2017), Martínez-López (2017), Rubio Terrado (2018) y Velducea Velducea et al. (2019). La categoría esencial de su pensamiento es la complejidad. Con ella hace alusión a los nexos múltiples y diversos en los cuales todo existe, mira al todo en su integridad y refiere la necesidad de articular.

Con frecuencia se usa el verbo 'articular' a partir de una de sus acepciones: unir dos objetos, o más, de tal manera que entre ellos haya li- 
bertad de movimiento. Ahora bien, cuando se usa esta palabra no se piensa tanto en otro de sus significados: organizar elementos para lograr un conjunto coherente y eficaz. Con estas dos acepciones Morin (2002; 2003; 2006) lo emplea; pero de sus textos se puede captar que su propósito final no es la articulación, sino el logro de la integración, no con el sentido de completar un todo con las partes que faltan, ni fusionar aspectos divergentes para arribar a su síntesis, sino para lograr la complementación, que es más que completar un todo con sus partes.

Esa idea no abunda de manera explícita en sus textos, no obstante, en algunas reflexiones la expone más o menos explícitamente, como cuando afirma que "el producto de la selección local, que es complementariedad, por tanto, integración” (Morin, 2002, p. 74). A propósito de esta afirmación vale acotar que 'complementar' es hacer que cada componente aporte a la existencia del todo, y de los otros componentes de este. Con esta aclaración puede captarse más fácilmente su espíritu integrador que explicita en las palabras siguientes: "El problema fundamental es, pues, restablecer y cuestionar lo que ha desaparecido con la disociación: esta relación misma" (Morin, 2001, p. 22), es decir, la articulación: propósito devenido en su pensamiento una constante, que se rebasa a sí misma, pues su pretensión va más allá de lograr articular algo por primera vez; su intención final, suprema, es la rearticulación y con ella el arribo a la integración de lo que está separado y que en otro momento estuvo articulado en un todo, lo cual es volver al estado anterior, pero ya en un nivel superior. Su fin (con sus propias palabras) es "la búsqueda de un método que pueda articular lo que está separado y volver a unir lo que está desunido" (Morin, 2001, p. 28).

En correspondencia, Morin (2001) afirma que es "de primera necesidad, no solo rearticular individuo y sociedad (...), sino también efectuar la articulación reputada de imposible (peor, de 'superada') entre la esfera biológica y la esfera antropo-social” (p. 22). Así, una de sus primeras intenciones es vincular las ciencias naturales y las sociales, acción que concibe en el marco de la reorganización del saber, que es donde comienza a desplegarse la esencia integradora de sus ideas, cuya corona es su concepción del ser humano como un trinomio: "individuo-sociedadespecie" (p. 22), donde ninguno de estos aspectos se reduce, ni subordina a los otros o a uno de ellos.

La anterior posición se corresponde con la solicitud de Morin (1999a) de exterminar en el siglo XXI el modo unilateral, fraccionador, de concebir al ser humano, ya fuera "por la racionalidad (homo sapiens), la técnica (homo faber), las actividades utilitarias (homo economicus), las 
necesidades obligatorias (homo prosaicus)" (p. 27) y comprenderlo como un ser complejo, cargado de contradicciones, comprensión esta consecuente con su modo de ver al ser humano de manera bipolarizada: cada una de las características humanas tiene su antagónico, y esto lo convierte en un ser complejo.

Ese modo de aprehender al ser humano se despliega a partir de dos aspectos que en el pensamiento de Morin (2001) se articulan en su misma base. El primero está dado por las reflexiones en torno a la oposición entre dos tipos de paradigmas científicos: el que fragmenta, separa y aísla para conocer y el que une y relaciona; no obstante, su crítica al primero, le reconoce su importancia y logros obtenidos con su empleo, pero subraya que hoy los diversos conocimientos y su desarrollo, muestran que no basta la visión que fragmenta pues "los conceptos-primeros ya no están aislados, ni son sustanciales, ni autosuficientes. Se religan y relativizan los unos a los otros" (p. 104). No rechaza lo simple, sino que condena la simplificación desmedida.

El otro aspecto básico para aprehender al ser humano está dado por los nexos entre lo biológico y lo físico, de los cuales asegura que se necesitan mutuamente. Afirma que antes de tratar la complejidad biológica es necesario tratar la complejidad física, no solo de un "ser-máquina/ informacional/comunicacional, sino también la de la conexión cósmica y la de la conexión microfísica donde la vida toma, entonces y solamente entonces, existencia a la vez autónoma y solar" (Morin, 2001, p. 417). Esta afirmación se debe a que Morin (2001) concibe la organización de la vida con un carácter eco-dependiente, desde donde subraya "la extrema fragilidad de sus condiciones de existencia, la extrema calidad de su organización, que le permite informarse y comunicar, y su extrema solidaridad con todos los fenómenos físicos de los cuales depende" (p. 416). Así, según su opinión (2002), la adaptación es no solo la subsistencia en condiciones geofísicas dadas, sino también la constitución de "relaciones complementarias o antagonistas con otros seres vivientes, para resistir a las concurrencias/competiciones y para afrontar los eventos aleatorios propios del ecosistema en el que se integra" (p. 70), o sea, que no solo está presente la religación, sino también la integración y con ella la complementación, cualidad que determina su esencia.

El propósito de integración también emerge en sus reflexiones en torno al conocimiento, que concibe como un fenómeno multidimensional, porque, de manera inseparable, es físico, biológico, cultural, social; porque conjuga procesos energéticos, eléctricos, químicos, fisiológicos, culturales, lingüísticos, colectivos, personales, impersonales, que se engranan unos en 
otros (Morin, 1999). Este criterio tiene cada vez más simpatizantes, aunque como hace saber Viguri Axpe (2019), no falta quienes solo ven valor científico en el conocimiento resultante de las llamadas ciencias duras.

Puede entenderse que Morin (1999), con ese posicionamiento, no mira con buenos ojos la separación entre las ciencias naturales y las humanas y el cierre entre ellas. Condena que este fenómeno se observa como si fuera natural, sin que se repare que es una manera de mutilar el saber y que origina un nuevo oscurantismo. Puede pensarse en la afirmación de los autores Vallejos y Coll (2017), que esta separación existe donde "las llamadas humanidades parecen estar desprestigiadas y su utilidad parece no ser la suficiente o estar muy alejada de las necesidades sociales del momento" (p. 109), aunque fatalmente, a veces el menosprecio no tiene ni la mínima justificación, mucho menos desprestigio e inutilidad.

El fraccionamiento contrasta con una de las exigencias del siglo XXI, apuntada por el autor Rodríguez Torres (2016): poseer un elevado nivel cognitivo que permita articular el conocimiento de manera adecuada, tanto para la solución de problemas, como para entender la vida en su totalidad, para cuya realización se ve como imprescindible saber relacionar los conocimientos nuevos y los previos, así como establecer conexiones entre distintos ejemplos de un concepto, que se traduce en el aumento de la capacidad para organizar una base de información cada vez más vasta.

Mas no es suficiente para Morin (2001) la rearticulación de los saberes; es imprescindible que se religuen el sujeto y el objeto del conocimiento: "Los más grandes progresos de las ciencias contemporáneas se han efectuado reintegrando al observador en la observación. Cosa que es lógicamente necesaria: todo concepto remite no sólo al objeto concebido, sino al sujeto conceptuador" (p. 23). En correspondencia, rechaza que se niegue la subjetividad porque se identifica con el error, y cuestiona la creencia de que este puede eliminarse por la concordancia de las observaciones y la verificación de las experiencias (Morin, 2001). En sus ideas (Morin, 1999), el investigador es parte de la investigación científica y no se debe segregar de ella. Así, como sostiene los autores Escobar y Escobar (2016), se posibilita que el sujeto exprese en la actividad científica su individualidad, sus sentimientos y pasiones su naturaleza humana.

Opina Morin (2001) que tal y como los objetos forman parte de su realidad física, los sujetos deben estar integrado a su cultura y a su sociedad, pero estas dos deben estar "integradas en la evolución biológica, la cual necesita ser integrada en la evolución organizacional de la physis, la cual remite de nuevo al observador-sujeto y así sucesivamente" (p. 405). Este camino lo sigue el autor Campero (2017), quien ubica al sujeto en 
una gran malla de relaciones, donde "se hace posible tanto la observación de un trazo integral del sujeto mismo como también permisible su propia indagación" (p. 136).

Morin (1999) asevera que "el conocimiento, que depende de condiciones físico-bio-antropo-socio-culturo-históricas de producción y de condiciones sistémico-lingüístico-paradigmáticas de organización, es aquello mismo que permite tomar conciencia de las condiciones físicas, biológicas, antropológicas (...) del conocimiento" (p. 34). En tal caso, donde el espíritu de complementación está presente, asegura que las condiciones socioculturales del conocimiento son, por su esencia, diferentes a las biocerebrales, pero se forman, conservan, transmiten y desarrollan a través de las interacciones cerebrales entre individuos, por tanto, no están aisladas; y aislarlas, es ir contra estas relaciones naturales. Este espíritu integrador lo extiende al interior de la cultura.

\section{Articulación entre la cultura científica y la humanista}

En el pensamiento de Morin (1992) la cultura es un todo que incluye en la sociedad y del cual destaca el papel de los conocimientos. Sobre esta base sostiene que las sociedades contemporáneas son policulturales, pues están integradas por tipos de cultura, entre ellos, las que denomina científica y humanista. Esta última la concibe centrada en el ser humano y con el propósito de esclarecer su conducta y sus relaciones con el mundo y la sociedad. La cultura científica la ve nucleada por la ciencia (solo las naturales y exactas). Se opone al corte epistemológico que se ha establecido entre esta y la cultura humanista, donde la moral y el conocimiento se comunican estrechamente, a diferencia de la científica, que se funda en la disyunción entre juicios de valor y juicios de realidad y se caracteriza por ser de especializaciones, de difícil acceso a quienes no formen parte de ella y por un crecimiento exponencial de los conocimientos que le corresponden, los cuales se encierran en disciplinas y se expresan en lenguajes formalizados, aptos solo para sus especialistas.

Condena Morin (1992) la ruptura de la comunicación entre las dos culturas y que cada una haya desarrollado su estructura y enfatiza, de ese modo, que el conocimiento científico "no se conoce a sí mismo: no conoce su papel en la sociedad, no conoce el sentido de su devenir, ignora las nociones de consciencia y de subjetividad, y con ello se priva del derecho a la reflexión" (p. 73). Tal separación es ilógica en esta época, cuando la ciencia y la tecnología se han convertido en un factor medular, a tal 
escala, que la actividad científico-tecnológica no solo compete a quienes la realizan; su impacto obliga a todas las personas a reflexionar en torno a ellas y sus consecuencias. Hoy, como asegura el autor Corona Fernández (2019), lo que requiere la sociedad es una reflexión crítica que rompa esa falsa idea y una lucha contra el esquematismo y la poca creatividad en la enseñanza de la ciencia.

\section{El espíritu integrador en las ideas éticas y acerca de la comunidad humana}

Las ideas de Edgar Morin que caben bajo este título (que las explaya, entre otros textos, también en Los siete saberes necesarios a la educación del futuro) son la causa de que, como recuerda el autor Vallejo-Gómez (2017), haya sido considerado un sociólogo planetario y un humanista.

En cuanto a la ética, uno de los objetivos integradores de Morin (2006) es el desarrollo de una autoética, que consiste, primeramente, en una reflexión en torno a la ética y, en segundo lugar, desde esta, la percepción al ser humano, en lo cual incluye la integración del observador en su observación y la vuelta sobre sí para comprenderse y corregirse, así como potenciar las semejanzas entre los seres humanos y, sobre esta base, posibilitar la fraternidad, $y$ relegar las diferencias a un segundo plano, porque esta favorecen la hostilidad.

Considera Morin (2006) que en la ciencia el exceso de separación es malo, pues impide religar los conocimientos y "para conocer, hay que separar y unir a la vez" (p. 114). Pero si ve que la separación es mala en la ciencia, la halla peor entre los humanos porque facilita las inquietudes, incertidumbres y angustias de la vida individual. Por eso llama a revertirla mediante la religación, que ve como "un imperativo ético primordial, que manda a los otros imperativos relativos al prójimo, a la comunidad, a la sociedad, a la humanidad" (Morin, 2006, p. 114), porque permite encontrar respuestas a las inquietudes e incertidumbres y conduce a las fuentes que posibilitan luchar contra la angustia.

Relacionadas con el anterior núcleo temático, toman consistencia en el pensamiento de Morin (2006) las interrogantes siguientes: ¿cómo comprender?, ¿cómo comprenderse a sí mismo?, y ¿cómo comprender a los demás? Considera que las respuestas han de estar en la conjugación de la comprensión objetiva, la subjetiva y la compleja. La primera está enlazada a la explicación, mediante la cual se articula la información que proporciona causas y determinaciones. La segunda tiene lugar entre su- 
jetos y va a los sentimientos y motivaciones interiores. La comprensión compleja engloba las dos anteriores y es multidimensional porque no reduce al ser humano a ninguno de sus rasgos y tiende a aprehenderlo con la diversidad de sus características y en varias dimensiones: psíquicas, culturales, sociales, históricas, así como lo singular y lo global. Estima que reducir un todo a uno de sus componentes es una falta intelectual, y que ello es peor en la ética que en la ciencia.

En las reflexiones de Morin (2006) en torno a la ética tienen un espacio sus ideas de la antropoética, que "lleva en si el carácter trinitario del bucle individuo/especie/sociedad y nos hace asumir así el destino humano en sus antinomias y su plenitud" (p. 176). Valga acotar que la palabra bucle hace alusión a un ciclo que vuelve y vuelve sobre sí mismo interminablemente, sin final. Según el propio Morin (2006), la antropoética eleva al nivel ético la consciencia de la unidad de todo lo humano en su diversidad, de la diversidad en todo lo que es unidad, y da valor a la misión de salvaguardar la unidad y la diversidad humanas.

Con esa posición establece nexos entre la ética de lo universal y la de lo singular. De la primera apunta que ha sido ahogada por éticas comunitarias cerradas y que ha podido emerger en las grandes religiones universalistas, aunque ha sido víctima de la pretensión monopolista de cada una de ellas y de su intolerancia. Señala, además, que se ha manifestado en las éticas universalistas laicas, en el imperativo kantiano y en la idea (aún por concretarse) de los derechos humanos. Acota Morin (2006) que era una idea abstracta "en tanto esa especie no se hubiera visto concretamente reunida, en conexión e interdependencia por el desarrollo de la era planetaria" (p. 176), que es para él comunidad de destino para la humanidad.

Dicha comunidad, al decir de Morin (2003), lleva en sí una conciencia del destino humano y que porta no solo peligros comunes, sino también una identidad compartida e insiste en la necesidad de que se tome conciencia "de que somos hijos y ciudadanos de la tierra-Patria" (p. 268). Esta idea del pensador francés, como opina el investigador Huertas Díaz (2015), es una orientación genuina a formar un pensamiento asociativo que se encamine a eliminar los sentimientos de exclusión y a fortalecer la solidaridad. Aquí está uno de los valores más colosales del pensamiento de Morin.

Es significativo en este caso destacar, como lo hace Restrepo Zapata (2017), la educación desde la identidad terrenal, en tanto guíe a los educandos a entender que cualquier decisión tiene repercusiones y que puede afectar a la humanidad en su conjunto. Por eso Morin (2003) subraya que "los re-enraizamientos étnicos o nacionales son legítimos a 
condición de que vayan acompañados del re-enraizamiento más profundo en la identidad humana terrestre" (p. 268), una de las grandes necesidades de la humanidad.

No ha de extrañar que el pensador francés (2003) considere que "el pensamiento que no percibe más que lo parcelario, lo fragmentario, lo descontextualizado, lo cuantificable, es incapaz de cualquier concepción global y fundamental" (p. 272) y que debe sustituirse la disyunción por la sabiduría de vivir unidos, que Morin (1999a) llama "simbiosofía" (p. 37), lo cual es no oponer la totalidad a las partes, sino ligarlas, esto es "integrarlas en el universo concreto de la patria terrenal" (p. 37). Idea esta que aumenta su brillo cuando sentencia: "Todas las culturas tienen sus virtudes, sus experiencias, sus sabidurías al mismo tiempo que sus carencias y sus ignorancias" (p. 37). Afirmación valiosa para estudiar no solo los tipos de cultura, sino también para adentrarse en las profundidades del papel que en ellas tiene lo académico.

\section{El carácter integrador en las ideas en torno a la educación del futuro}

Las ideas de Morin (1999a) acerca de este tema están relacionadas con la integración del cognoscente en su conocimiento como un principio y una necesidad permanente de la educación, lo cual exige que se comprenda que para el desempeño de la misma hay condiciones bioantropológicas y socioculturales que permiten la formulación de interrogantes sobre el mundo, el ser humano y el conocimiento. Considera que en la docencia son muy importantes las preguntas hacia los alumnos. Vale traer a colación la afirmación del autor Álvarez Nieto (2017) de que en la actividad académica el reconocimiento de la incertidumbre va aparejado a la toma de conciencia del inacabamiento y a evitar las simplificaciones, las facilidades ficticias y las incoherencias burdas. A su vez, amerita tener en cuenta la idea de Ruiz Lara y Torres Soler (2016) en cuanto a que la estimulación de la curiosidad, la imaginación y el descubrimiento de lo oculto, impulsan al estudiante a querer investigar.

Respecto a la educación del futuro, en el pensamiento de Morin (1999a) sobresalen dos consideraciones que evidencian el carácter integrador de sus ideas. Una de ellas es la urgencia de superar el tipo de educación, según el cual se enseña "a separar, compartimentar, aislar y no a ligar los conocimientos" (p. 18) por lo cual el conjunto de los conocimientos se torna una especie de rompecabezas ininteligible y se vuelven 
invisibles las interacciones, las retroacciones, los contextos, las complejidades y se acrecienta la incapacidad de organizar el saber disperso y compartimentado, de contextualizar y globalizar, así "los grandes problemas humanos desaparecen para el beneficio de los problemas técnicos y particulares" (p. 18). A propósito de estas ideas es oportuno mencionar la opinión de Álvarez Del Valle et al. (2019), en cuanto a que a la luz del pensamiento complejo cobra vigor la integración de conocimientos, habilidades y actitudes, lo cual es cierto, pero no se puede perder de vista la apertura a la hora de concebir la integración, ya que esta, por ejemplo, puede quedar atrapada en el marco de una especialidad (científica o académica) y así cerrarse a lo otro; de ahí la importancia de la apertura.

La otra de esas dos ideas es construir para el mañana una educación que religue los conocimientos de las ciencias naturales y los de las ciencias humanas, para aclarar las multidimensionalidades y complejidades humanas y cuidar que la idea de "unidad de la especie humana no borre la de su diversidad, y que la de su diversidad no borre la de la unidad" (p. 25). Es no perder de vista la relación dialéctica entre la unidad y la diversidad, pues como él sentencia: "Hay que concebir la unidad de lo múltiple, la multiplicidad del uno" (p. 25), que es conservar la diversidad humana.

La idea acerca de las relaciones entre la educación, las ciencias naturales y las ciencias humanas invita a reflexionar sobre el quehacer de las universidades, sobre todo si se busca una formación integral de los estudiantes; a ello se le puede sumar que, tal y como apunta el estudioso Vega Cárdenas (2016), la mayor parte de la obra de Morin, particularmente Los siete saberes necesarios para la educación del futuro, sirve de guía para inspirar los cambios necesarios en los sistemas educativos y formar profesionales íntegros y capaces de vivir adecuadamente en la sociedad venidera. A todo ello se le puede sumar la afirmación que ofrece el filósofo cubano Guadarrama González (2018) en cuanto a que si los investigadores y profesores tienen presente el pensamiento de Morin pueden evitar reduccionismos epistemológicos. De tal suerte, el espíritu integrador del pensamiento morineano es un acicate en la aspiración de reforzar el carácter integrador de la formación universitaria.

\section{El carácter integrador de la formación universitaria: vigencia del pensamiento de Edgar Morin}

La importancia de la ciencia y la tecnología crece sin cesar, y a su vez, aumenta también la valía de quienes están relacionados con ellas, entre 
los cuales figuran los profesionales universitarios. Estos tienen un lugar destacado por su elevada preparación como especialistas y por su participación, muchas veces decisiva e insustituible, en los diversos procesos científicos y tecnológicos; con el incremento de su trascendencia, se agranda al mismo tiempo el valor de la formación universitaria.

\section{En torno a la categoría 'formación' y a su uso en el ámbito académico}

Es oportuno precisar el significado de la palabra 'formación', que se emplea en muchos contextos y tiene varias acepciones; en el caso del nivel universitario se relaciona con la preparación de un especialista de rango mayor, apto para desempeñar determinadas tareas y hacerlo con elevada calidad.

La palabra formación procede de forma; su acepción más temprana fue a dar forma, que luego se enriqueció con el significado de criar, adiestrar, educar; mediante esas dos vías se tejen relaciones con el accionar académico. Venegas Renauld (2004a) señala que la palabra de referencia tiene entre sus significados, informar, a partir de la idea de in-formar, es decir, incorporar datos, ideas, información, de donde también se construye una malla de nexos con la labor escolar e invita a tener presente que el término instruir tiene entre sus significados, informar. $\mathrm{Al}$ mismo tiempo, esta autora hace saber hay algo más y es que otra acepción de la palabra 'formar' es adquirir una persona desarrollo, aptitud o habilidad en lo físico o en lo moral, con lo cual formación más que formar, da otra idea: formarse. Con esta aclaración se persigue destacar que el carácter activo de quien se está formando no es simplemente un resultado ideológico del momento, sino que la propia palabra porta ese significado en su andar.

En el contexto académico la categoría 'formación' es complicada, no solo porque la palabra es polisémica, sino también por la cantidad de criterios variados que existen en torno a ella, aunque no faltan textos donde se emplea sin una mínima definición, por lo que su significado se debe deducir de los objetivos que se persiguen con ella o del contenido del propio escrito; así sucede en el de Duarte Díaz y Valbuena Ussa (2014). No pocas veces, como en el artículo de Bizquerra (2005), se entiende en relación con el hecho de dotar a las personas de conocimientos que la preparan para alguna función social específica, mientras que en otros, por ejemplo el de Cuervo Ballesteros (2017) y el de Pérez Guzmán (2018), se relaciona con el desarrollo de características profesionales o humanas generales, tales como conocimientos, manejo de las emociones, 
comunicación, pero con la finalidad expresa de que se empleen y manifiesten en acciones concretas. En otros trabajos, entre ellos el de Álvarez (2017), se concibe estrechamente relacionada con la cultura y la sociedad $\mathrm{y}$ se asocia al quehacer encaminado a darle forma a las capacidades y facultades naturales de los individuos para que asciendan a la generalidad.

Cuando se le pregunta a alguien cuál es su formación, es muy común que responde haciendo referencia a los estudios cursados, los títulos y reconocimientos obtenidos, es decir, se asocia, ante todo, a la academia y a la preparación que se ha obtenido en ella. La autora González Rivero (2016) asegura que la profundización en la literatura especializada en este tema le ha permitido apreciar que el vocablo formación tiene una historia larga como categoría en filosofía y en otras especialidades, sobre todo la pedagogía (donde su uso es sumamente frecuente), sin embargo, "son limitados los trabajos que realizan estudios extensos sobre él pues generalmente aparece aludido de manera tenue o como un rasgo que no necesita mayor explicación" (p. 153), y de tal carencia se lamenta con frecuencia. Esta es una condición de por qué, según ella misma afirma, "generalmente se asume en atención a sus características más superficiales" (p. 154) no hay suficiente claridad teórica, se usa desde perspectivas distintas y "no se encuentra en general un desarrollo teórico al respecto" (p. 154).

González Rivero (2016) afirma que en el estudio de la categoría de marras en el ámbito académico se distinguen dos perspectivas; una se extiende desde el exterior del sujeto en formación y la otra desde el interior del mismo. Asevera que no pocos estudiosos asumen la primera variante, desde donde la formación se concibe como una influencia que se ejerce sobre un sujeto (que deviene su objeto) y que se concibe como un proceso o sistema de acciones para actuar sobre un sujeto y realizar un propósito formativo. La otra perspectiva, la de la interioridad, es, según apunta González Rivero, reciente, poco estudiada y con escaso desarrollo teórico, aunque aclara que el hecho de considerar al sujeto como elemento esencial de la formación tiene raíces largas. Señala que la idea rectora de esta variante es que la formación es "una especie de función propia del ser humano que se cultiva y puede desarrollarse: la función evolutiva" (p. 163) y puntualiza que aunque al respecto hay diferentes criterios, desde este ángulo, en sentido general, la formación se concibe como la apropiación incesante que el ser humano efectúa a lo largo de la vida. En correspondencia con esta última modalidad, enfatiza que en el proceso formador es decisiva la voluntad de quien se está formando, su "decisión y autovaloración para implicarse o no en su propia transformación” (p. 166). 
Independientemente del valor que tiene cada una de esas perspectivas, vale acotar que ambas por separado son muestra de una percepción fraccionadora; las dos existen en relaciones dialécticas. La formación es un proceso interior-exterior-interior, es un intercambio creativo entre el sujeto y lo externo a él, de donde toma lo que desea, e incorpora lo que selecciona, ya sea por decisión propia o por la acción externa (influencia, insistencia, obligación). La formación no es que debe ser por voluntad propia, es que en su realización es decisiva la voluntad propia, el convencimiento y las convicciones, en nexos con el mundo externo: se toma de él y se lleva a él continuamente; de ahí el papel cardinal de la persuasión, de las orientaciones, de la guía.

A propósito de lo anterior, vale subrayar que la formación no es autoformación, pues aunque el papel decisivo lo tiene el componente subje108 tivo de quien se está formando, o sea, su voluntad, decisión, perseverancia, conciencia, en la formación es importante la influencia externa y el juego dialéctico entre lo subjetivo y lo objetivo, si no el sujeto se enclaustrara en sí mismo; de aquí el papel valioso del formador y no solo como guía, sino también como impulsor. Vale mucho atender el proceso enseñanzaaprendizaje, pero hay que centrar más la atención en el aprendizaje.

En el contexto académico la categoría de referencia alude a un proceso donde están presentes lo histórico, lo social, lo filosófico, de ahí su amplitud. Esta característica, si ciertamente la hace muy complicada, también la dota de grandes posibilidades teóricas y de un amplio y diverso alcance práctico. Cuando se emplea en el marco académico se relaciona con otras categorías no menos complicas y polémicas: educación y desarrollo.

En el marco mencionado, esas tres categorías están dialécticamente relacionadas entre sí pues aluden a un proceso en su complejidad; cuando se usan por separado es con la finalidad de puntualizar teóricamente. Así, con la categoría educación se puede referir lo concerniente a moldear rasgos, cualidades, principios, existentes con la intención de cambiarlos o crear otros; por ende, moldeando, se forma. Mientras tanto, la categoría formación enfatiza, destaca, que se crea algo nuevo, superior a lo existente, en lo cual hay desarrollo, pero también moldeo; es decir, en el hecho de formar, hay educación y desarrollo. Valga abrir un paréntesis y con él una acotación a propósito de la autora Venegas Renault (2004) y es que ubica el despunte del empleo pedagógico de la palabra 'formación' en el marco del concepto educación durante el Renacimiento, "en un lento proceso de diferenciación" (p. 30) y lo relaciona a la obra del pensador Erasmo De Rotterdam (1466-1536). No ha de extrañar, entonces, los vínculos entre ambas categorías. La formación lleva implícita la educación y el 
desarrollo; solo con una visión rígida y limitada se concibe la formación en el contexto académico como el hecho de formar algo estático, que no cambia, que no se desarrolla de alguna manera.

Es oportuna una aclaración: A la luz de las corrientes empiristas y positivistas, la palabra 'forma' tiende a reducirse a relaciones que pueden generalizarse por la verificación de una regularidad comprobada en los hechos. Venegas Renauld (2004a), asegura que con esta influencia filosófica en las ciencias modernas llega a sustituirse la palabra 'forma', "por términos sustantivos y no verbales, como 'estructura', con un significado de regularidad, asociándose más al aspecto de estructura estática, que al funcionamiento dinámico" (21), así puede hallarse en la geología y en el universo militar, que alude a la estructura y con ella, a un determinado orden, a una composición u organización.

La fuerte carga educativa que porta la categoría formación en el plano de la academia, lleva a algunos autores, como sucede con FerradaSullivan (2017), a que la reflexión que inicia en torno a la formación tome un rumbo que la lleva directamente a la educación y a ubicar a esta en el centro de los análisis.

Por lo general, cuando la categoría formación se tiene en cuenta desde la perspectiva académica, se asocia al proceso docente-educativo y se ve como una parte suya, que, al decir de algunos autores, como Ramos Serpa (2006) y Zabalza (2011), puede entenderse por áreas: formación política, económica, jurídica, y por profesiones: profesoral, médica, jurídica; en todos los casos ligada a la adquisición de nuevos conocimientos y a la reacomodación de los existentes, así como a las habilidades y destrezas. En correspondencia, Vázquez Alonso (2014) y Velásquez Jiménez (2016) asocian a ella el conocimiento de la especialidad que se imparte y a las competencias que deben tener los profesionales de la misma. En general, en su empleo no falta la mirada a lo educativo y lo didáctico, aunque el grado de atención puede ser mayor o menor, en dependencia de los intereses que tenga quien la está estudiando, es decir, de los propósitos de investigación y de las posibilidades de los investigadores.

En el universo de criterios y especificidades en torno a la formación, vista desde la perspectiva académica, hay una variante esencialmente integradora, la socioformación. En el trabajo de Vázquez et al. (2017), se aprecia que el núcleo de esta modalidad son los retos sociales y ambientales, así como las necesidades de autorrealización personal y su intención es que las personas aprendan a identificar, interpretar, argumentar y resolver problemas de manera colaborativa, con un proyecto ético de vida, así como que desarrollen su capacidad de emprendimiento. La 
amplitud de este espíritu se observa en el texto de los autores Balladares et al. (2016) quienes entienden la formación como un quehacer donde se involucren al mismo tiempo más de una disciplina docente.

Existen otras variantes integradoras que rebasan los límites de lo estrictamente académico. Una de ellas es la que tiene la finalidad de formar (y desarrollar) en la persona su condición de ciudadano; así se habla de formación ciudadana, que al decir de González Rivero (2019) es un "proceso sistemático, intencional y continuo de socialización, que tiene el propósito de promover en la persona su condición de ciudadano" (p. 343); esto es desarrollar en los seres humanos la capacidad para que participe plenamente en la sociedad, o sea, para que devenga un actor social, propósito este que rebasa los límites de prepararlo para que participe activamente en los destinos de su comunidad, pues este tipo de formación 110 tiene en sus cimientos la "actitud crítica, reflexiva y creativa para realizar transformaciones en torno al bienestar humano" (p. 343). Es de destacar que la formación ciudadana, la cual incluye no solo conocimientos, sino el desarrollo pleno de la personalidad, es "una concepción que no cuenta con estudios suficientes" (p. 348), a lo cual se le puede agregar que así sucede con la categoría formación en el plano académico, aunque esta afirmación parezca exagerada y categórica.

Otra visión integradora y sumamente amplia, es la denominada formación humana, cuya finalidad es formar seres humanos, o sea, formar características en los seres humanos que los hagan mejores, es decir, que los humanicen, que los hagan ascender a escalas superiores en el proceso de humanización; en voz de Pacheco González y Pupo Pupo (2017) "se asienta en el objetivo de formar seres humanos" (p. 52).

Después de un recorrido por varias comprensiones en torno a este tema, se puede afirmar que la formación como categoría académica constituye un sistema y, al mismo tiempo, un proceso, donde hay relaciones de diversas índoles, que pueden observarse en etapas y niveles, siempre matizadas por las condiciones histórico-sociales concretas y por los nexos entre el accionar externo a cada individuo y su universo espiritual (la capacidad racional y la afectividad, con los resultados de cada una y sus vínculos mutuos), aunque su rasgo identificador es que en ella el rol determinante lo tiene la conciencia de quien se está formando y su subjetividad: convicciones, aspiraciones, propósitos, ideales, que son impulsos para vencer obstáculos, alcanzar metas y rebasarlas. 


\section{La formación universitaria a la luz del pensamiento complejo}

Al hablar de formación en el contexto académico y como se ha dicho de diversas maneras a lo largo de este texto, es imposible ignorar o menospreciar el inusitado desarrollo científico-tecnológico; pero tal nexo es mucho más sólido cuando se trata de la formación universitaria, pues, como es archiconocido, sus resultados son los profesionales, quienes se desempeñarán en diversas áreas decisivas para la sociedad, muchas de ellas ligadas a la ciencia y la tecnología. No es difícil entender que la calidad del desempeño de los profesionales depende en gran medida de cómo se realizó su formación, de su amplitud, profundidad y alcance. Por eso tiene gran importancia uno de sus rasgos esenciales y que más demanda el referido desarrollo: la integridad, para la cual es valiosa la perspectiva que se logra cuando se asume el pensamiento complejo, cuando se atiende las reflexiones y sugerencias de Edgar Morin.

En este sentido es oportuno subrayar la recomendación de Hernández y Figuerola (2016) en cuanto a que en la formación universitaria ha de prevalecer una óptica integral, que se despliegue a través de la conjugación de acciones externas e internas (con el papel determinante del componente subjetivo de quien se está formando y con la mayor amplitud alcanzable. Es bueno recordar, como señala González Velasco (2019), que cuando estas faenas se realizan con una visión reduccionista "el aula no deja de ser vista como espacio cerrado" (p. 38), a lo cual se debe añadir que resultantes de tal mirada son, asimismo, profesionales cerrados, quienes, en tanto son frutos de una mentalidad estrecha, unilateral, seguramente se encargarán de reproducir estas características, y estos no los profesionales que necesita la sociedad actual; hoy la formación debe ser integradora.

No bastan los conocimientos y habilidades profesionales para que los graduados universitarios se desempeñen con éxito en su profesión, pues si la sociedad actual requiere apertura mental y racionalidad flexible, en resumen: una mirada integradora, también necesita tener profesionales que cumplan esas exigencias; de ahí la importancia de que la formación sea cada vez más amplia y abarcadora, lo cual no puede entenderse como superficial, ni de generalizaciones. Esta concepción exige una visión compleja y dúctil, que, teniendo en cuenta las potencialidades de los individuos, sus iniciativas y autonomía, se encamine, como recalca el autor Castellanos (2016) a "la integración de conocimientos, habilidades, motivos y valores que se expresan en un desempeño profesional eficiente, ético y de compromiso social" (p. 148) junto a la autonomía, la flexibili- 
dad y la capacidad de asumir cambios vertiginosos, de transformarse a sí mismos en correspondencia con los cambios de la sociedad y de ser capaz de hacerla andar siempre rumbo a un futuro mejor.

Una línea estratégica para este tipo de formación, como aseguran Escobar y Escobar (2016) es que se propicie espacios de encuentro "para que lo uno converja con lo otro, lo único con lo múltiple, lo individual con lo grupal, y la subjetividad se vea enriquecida por la objetividad relacional de todos con todos y de todos para todos" (p. 96). Hace falta transformar el pensamiento y, al decir de Ruiz Lara y Torres Soler (2016), también es necesario crear espacios que lo propicien y abran vía a la creatividad.

A la luz del pensamiento complejo, cuando se diseña la formación de profesionales universitarios es oportuno que se coloque en el centro de atención a las personas a quienes se va a dirigir el accionar forma112 dor. Este modo evita la presencia de aspiraciones utópicas, centradas en el profesional concebido como objeto y no como sujeto histórico-social concreto; asimismo propicia que este sea activo en dicho proceso y que participe desde los espacios donde vive, pero esto también evita, como acota Castellanos (2016), el desbalance entre el contexto real de formación, la persona concreta y el currículo.

Son varios los rasgos que caracterizan al currículo cuando se concibe desde el pensamiento complejo, González Velasco (2017) señala los siguientes: integración disciplinaria, retroactividad, recursividad y reintroducción, apertura, flexibilidad, carácter dialógico, gran sentido social y humanista, por lo cual es importante la atención a las dimensiones personales y sociales, a los valores, la cultura y la conciencia planetaria, enarbolada por Morin. Esta concepción se sustenta en el objetivo de formar hombres y mujeres con criterio propio, autónomos y, como enfatiza Maldonado (2017), con sensibilidad al entorno natural y social, para que sean capaces de resolver los problemas que aparezcan, de los cuales la mayoría serán concernientes a los humanos. El propósito que se tiene con este tipo de currículo es formar seres humanos y, por tanto, es en sí, formación humana.

No es superfluo recalcar que ese modo de concebir la formación le urge a la sociedad humana actual, sobre todo en cuanto al desarrollo del pensamiento crítico y creativo y de ello no puede ser ajena la formación universitaria. Tal propósito se favorece cuando la alta casa de estudios es un espacio de diálogo abierto, impulsado por objetivos emancipadores. Y aquí el espíritu integrador es el vigor para ir adelante y la brújula que marca el camino; entonces sus contrarios y negadores son el fraccionamiento y la sobrestimación de unos aspectos en detrimento de otros. La parcialización influye negativamente en la creatividad, como demuestra 
un estudio realizado al respecto por Cabrera Cuevas y De la Herrán Gascón (2015), dos investigadores de la Universidad Autónoma de Madrid. Ahora bien, para llevar adelante esta obra, es imprescindible formar formadores con un pensamiento complejo, que significa, entre otros aspectos, que se opongan al fraccionamiento arbitrario y se propongan la integración y la complementación.

He ahí una muestra del valor metodológico y de guía del pensamiento de Edgar Morin en toda obra formadora, incluida la formación universitaria, donde todavía hay fraccionamiento, que se observa no solo en la separación y el aislamiento de características, propiedades o propósitos, sino también en la persistencia de la sobrevaloración de alguno de ellos, que es una manera reducida de entenderlos. El reduccionismo es resultado del fraccionamiento y la separación.

\section{El componente laboral de la formación universitaria. Una mirada a través del pensamiento complejo}

En los trabajos de Balladares et al. (2016) y Velducea Velducea et al. (2019), puede observarse que en la formación universitaria existe la tendencia a priorizar la enseñanza de contenidos de asignaturas y a relegar a planos inferiores el desarrollo de destrezas y habilidades cognitivas. Esta modalidad está favorecida por las crecientes relaciones de las instituciones universitarias con los conocimientos científicos y tecnológicos, que abarcan su consumo, producción, difusión y almacenamiento. Dichos conocimientos y los productos resultantes, se diseminan por la sociedad y, no pocos de ellos, devienen objetos de comercio. Tal característica ha facilitado la existencia de una mirada empresarial a las instituciones universitarias y se ha intensificado la pretensión de que respondan a las exigencias del mercado, por lo cual, como apunta el autor Brower Beltramin (2014) crece el modo de atenderlas como si fueran una empresa más, o un apéndice de la industria y no faltan estudiosos, como Restrepo Zapata (2017), quienes subrayan el deseo de que la formación profesional satisfaga las exigencias de las empresas y el mercado y como BermúdezAponte y Laspalas (2017) quienes destacan la capacitación en función de los mismos y piensen que "los profesores deben comportarse como emprendedores o vendedores" (p. 113). No obstante, y por suerte, hay estudiosos, como el propio Brower Beltramin (2014), quienes piensan diferente y opinan que esa posición es una distorsión del sentido esencial de la formación universitaria. 
Vale aclarar que uno de los objetivos centrales de la formación universitaria es formar en los estudiantes competencias laborales. De esto no caben dudas, ni recelos. Este propósito es incorrecto, no es dañino, ni malo. Lo que sí resulta ser perjudicial es que dicha formación sea reducida a ese objetivo, no solo porque se subordina a los mandatos mercantiles y a la satisfacción de las exigencias de los posibles puestos de trabajo y del mercado de los mismos, sino también porque atenta contra la amplitud consustancial a la universidad y al quehacer formativo suyo.

La formación del componente laboral es una tarea sumamente complicada y de crecientes exigencias, además, a la que no se le debe restar importancia, pero tampoco sobrevalorar. Si se sigue la lógica de Edgar Morin, el quid del asunto está en que el profesional no es solo un trabajador. Si la formación universitaria se limita a determinadas cualidades, se mutila su misión, que es formar a un profesional competente y a un ser humano, en la integridad históricamente alcanzable, es decir, en sus múltiples relaciones sociales y no solo las laborales. Si se atiende única o preferentemente un componente del quehacer formativo, otros quedan relegados a planos inferiores, o excluidos.

Si prevalece un enfoque utilitarista, en el que el estudiante se especializa en resolver situaciones laborales puntuales, la universidad se convertirá en un mecanismo que genera egresados con capacidades instrumentales para propósitos específicos. La sobrevaloración del componente laboral consiste no solo en que los conocimientos se conciben en función únicamente de la profesión, sino, como se puede captar en el texto de Aguilar Astorga (2017), que esta se convierte en algo encerrado en sí mismo y, por tanto, aislado y aislante. Al decir de Rodríguez (2017), la formación de profesionales capaces exclusivamente para el trabajo, es propia de los siglos XIX y XX y, por tanto, es un residuo del pasado.

Según los autores Navia-Antezana y Hirsch-Adler (2015) y Picazo et al. (2018), hay experiencias que demuestran que el componente social es a veces mejor valorado (como rasgo deseable de un buen profesional) que el componente técnico o cognitivo. Esto demuestra que no faltan quienes reconocen que los individuos formados en aspectos puramente prácticos, a final de cuentas no poseen habilidades sociales y humanas, también muy necesarias para desempeñarse con éxito en el ámbito laboral. Pero lo llamativo es que en tales circunstancias también se corre el riesgo de ir a un extremo y con ello, sucumbir en los brazos de otro tipo de reduccionismo.

Existen estudiosos, como Ciurana y Regalado Lobo (2017), a quienes inquieta el reducción, tanto el que se observa en la sobrevaloración 
del propósito de formar profesionales con alta preparación para cumplir las normas técnicas de modo eficiente, con capacidad para adaptarse a los cambios tecnológicos y obtener de ellos resultados óptimos y el que tiene lugar cuando se centra la atención de la satisfacción de las exigencias del mercado laboral y tecno-industrial, como cuando se sobredimensiona este objetivo y quedan en un plano inferior otros aspectos muy importantes en la vida de un individuo y de la sociedad, por ejemplo, el desarrollo del pensamiento crítico y creativo y la formación de hombres y mujeres como ciudadanos, aptos para vivir activamente en la comunidad a la cual se deben. En toda esta faena no ha de olvidarse el enriquecimiento del universo espiritual, para lo cual tiene una incalculable valía el estudio de la filosofía, la ética, la estética, la historia, el arte, la literatura artística y la lengua materna.

No basta un graduado universitario que solo tenga óptimas cualidades laborales. Una de las grandes tareas que tienen hoy los profesores es propiciar que los alumnos aprendan a orientarse en la enorme cantidad de información existente y a entender que esta es un medio para lograr un fin: conocer, con creciente profundidad, la naturaleza y al ser humano, con los resultados de su creatividad. En correspondencia, los docentes tienen ante sí el desafío de motivar a los estudiantes a investigar la raíz de los fenómenos y a aprender a valorar el conocimiento no solo en su valor intrínseco, sino también en función del ser humano.

La formación universitaria debe moldear todas las capacidades y facultades de los alumnos, no únicamente para satisfacer las exigencias económicas o políticas del momento, sino para avanzar en el camino del mejoramiento humano, que, aunque se corresponde con lo alcanzable según las circunstancias, al mismo tiempo constituye una instigación para avanzar a niveles superiores.

\section{Lo racional y lo afectivo en la formación profesional universitaria}

Los cambios que experimenta la humanidad no han podido eliminar la mentalidad tecnocrática y pragmática, según la cual lo más importante son la tecnología y la solución de los problemas prácticos, propósitos estos que no son ni perversos ni erróneos, mientras no se absoluticen. Conforme a este tipo de pensamiento, las profesiones existen solo para solucionar tales problemas y la vía que se concibe como idónea para satisfacer esta exigencia y hacerlo con rigurosidad, es la del empleo exclusivo de la ca- 
pacidad racional, porque se concibe que es a través de ella que se logra la objetividad y la pureza científica del conocimiento, que es su fin último. Aquí se está en presencia de dos tipos de reduccionismo: las profesiones 'solo' sirven para resolver problemas prácticos y vale 'exclusivamente' la capacidad racional, porque nada más se llega a la objetividad mediante ella, por tanto, se excluye lo subjetivo (valoraciones, creencias, pareceres).

La elevada atención al componente laboral de la formación profesional universitaria va aparejada a la estimación exclusiva de la capacidad racional. Se comparte el criterio del autor Martínez (2015), quien enfatiza que así se olvida el papel básico que tiene la afectividad en la vida humana. Vale mencionar el estudio exploratorio realizado por la profesora Curiel León (2018) en la Universidad de La Habana con el cual constató que en la docencia objeto de su estudio se enfatizaba el dominio del sis-

116 tema conceptual de cada asignatura y disciplina, se le brindaba menor atención al plano afectivo y que en los docentes existían necesidades de formación relacionadas con el conocimiento de sí mismo y lo afectivo.

Ese hecho no es exclusivo de la Universidad de La Habana, ni siquiera de Cuba. Inquieta a muchos profesores de todo el mundo y de todos los niveles el predominio del enfoque intelectualista y la relegación de los aspectos afectivos a planos inferiores o nulos, entre ellos Fernández et al. (2009), Castañeda Serna (2014), Barrantes-Elizondo (2016) y Ojalvo Mitrany y Curiel Peón (2018). No obstante, este interés y la afirmación, con ganada autoridad, del filósofo español José Antonio Marina (2005), de que la bibliografía en torno a la educación emocional es amplísima, en cuanto a la formación universitaria no es notoriamente abundante la cantidad de textos dedicados a estudiar estos asuntos, no solo lo emocional, sino también lo afectivo en su integridad. Tal afirmación, que se limita al mundo de la lengua española, se puede comprobar con una búsqueda bibliográfica que abarque diversas revistas, de cualquier país, en las cuales pueda haber estudios de universos temáticos afines. Dicha aseveración no niega la existencia de trabajos profundos y actuales, como los de Fragoso-Luzuriaga (2015) y Curiel et al. (2018), aunque es notable, como puede verse en el texto de León et al. (2019), la concentración de la atención en lo racional.

En cuanto a la formación universitaria, es necesario aumentar la teorización en torno a lo afectivo, sobre todo en la actualidad, cuando en los tiempos que corren las altas casas de estudios están marcadas por tensiones resultantes de transformaciones y exigencias internos y de la sociedad, dados en gran medida por los avances de la ciencia y la tecnología, 
donde sobresale la escasa atención a lo afectivo y descuella la polarización maniquea entre este y lo racional.

La afirmación anterior no significa que no crezca el número de estudiosos quienes reconocen que en los vínculos afectivos hay un gran potencial para que sea más eficaz el proceso de enseñanza-aprendizaje; ejemplos son Maldonado-Torres et al. (2018) y Goicoechea Gaona y Fernández Guerrero (2014). Estos últimos recomiendan que se tome "en consideración todas las dimensiones afectivas que han sido olvidadas por los discursos científicos y filosóficos tradicionales" (p. 45), a lo cual vale añadir que es imprescindible tener en cuenta esta idea, porque la formación no es un quehacer frío.

Urge fortalecer el componente afectivo y hacerlo como un proceso intencionado para promover la expresión adecuada de emociones, sentimientos y pasiones e incentivar el autoconocimiento. En la formación universitaria no se puede prescindir del razonamiento, ni de la rigurosidad de la disciplina intelectual, pero es necesario el equilibrio entre lo racional y lo afectivo.

Es importante la presencia de ambos en una medida equilibrada. Y es aquí donde radica el problema, pues ha habido una parte favorecida o que ha acaparado sobre sí mayor atención: la racional. Se hace necesario subrayar el componente afectivo y atenderlo de manera específica. Es necesario y conveniente, como se puede entender del texto de Bisquerra Alzina (2005), que los profesores universitarios conozcan el trabajo que se realiza respecto a lo afectivo, se sientan estimulados a aplicar los resultados en su quehacer formativo cotidiano, no solo docente, y a escribir sobre sus consideraciones y experiencias en torno a esta temática. Es posible, solo basta proponérselo. La afectividad, las manifestaciones afectivas, no son privativas de las féminas, ni de las humanidades. Hay tanta afectividad masculina, como femenina, y las matemáticas, la física o las ingenierías pueden provocar lo afectivo tanto como un poema o una obra de teatro; cada una con sus especificidades.

No es superfluo volver a Morin (1999) y subrayar que enfatiza la necesidad de entender que la razón y la afectividad existen en estrechas relaciones y no hay por qué observarlas separadas, ni concebirlas opuestas. Tampoco está demás recalcar la atención que le brinda a la creencia de que con el rechazo a la afectividad se elimina la posibilidad de cometer errores, a lo cual apunta que al sostener tal credo no se piensa que, si ciertamente lo afectivo puede asfixiar el conocimiento, también puede fortalecerle. Es oportuno, asimismo, enfatizar que la observación de los nexos entre lo racional y lo afectivo también lo conducen a afirmar que si es cierto que 
"la facultad de razonamiento puede ser disminuida y hasta destruida por un déficit de emoción; el debilitamiento de la capacidad para reaccionar emocionalmente puede llegar a ser la causa de comportamientos irracionales" (p.5).Y expone con energía ostensible un principio de la lucha contra el paradigma científico simplificador y disyuntivo y, a su vez, a favor de su opuesto, aquel otro, el integrador y complejo, cuando asevera que "el odio, el amor y la amistad pueden enceguecernos; pero también hay que decir que ya en el mundo mamífero, y sobre todo en el mundo humano, el desarrollo de la inteligencia es inseparable del de la afectividad" (p. 5).

En el caso específico de los estudiantes universitarios, y desde una perspectiva de utilidad práctica, vale enfatizar que el manejo inteligente de las emociones propias y ajenas, puede ser una herramienta que contribuya a que cumplan sus metas, que sean más competentes y se formen 118 integralmente. Es inteligente quien dirige su afectividad con inteligencia y es afectuoso quien expresa su inteligencia con afectividad. Posee gran valía el saber conducir las afectividades hacia un objetivo y alcanzarlo cumplir. Los sentimientos, las emociones y las pasiones pueden estimular el optimismo y el espíritu emprendedor. La vida en sociedad puede ser más cómoda si se sabe reconocer la afectividad de los demás seres humanos; al saber interpretarla (con los gestos, las expresiones del rostro, el tono de voz) se facilita el hecho de ponerse en el lugar del otro, tener empatía y mejorar las relaciones humanas y, a su vez, enfrentar los desafíos del presente y el futuro. Vale tenerla presente y no solo ante lo positivo, sino también ante lo negativo; esta es una vía para entender lo que debe reforzarse o transformarse y con cuál rumbo.

A propósito de las relaciones entre lo racional y lo afectivo vale la referencia a un cuerpo teórico denominado neuroeducación. A su luz, como puede hallarse en los escritos de Mora (2015), se reconoce que las emociones y los sentimientos son pilares esenciales para el proceso enseñanza-aprendizaje ( $y$, por extensión, también lo son para la formación universitaria) y que las emociones son un motor que cada cual lleva dentro de sí, que mueve a querer estar vivos en interacción con el mundo y con sí mismo, lo cual es una reacción inconsciente que propicia la supervivencia, aunque en los seres humanos se hace consciente.

Cercano a esos criterios está otro, que puede hallarse en el trabajo de Bueno Torrens y Forés Miravalle (2018), y es que el aprendizaje se consolida mucho más y se puede aplicar más a situaciones nuevas cuando consigue movilizar emociones y raciocinio, así como que para aprender se ha de estimular la capacidad de querer saber, pues son muy importantes lo significativo, la motivación, las emociones y sobre todo el placer. 
Si se piensa en correspondencia con la visión compleja de Edgar Morin, se pueden entender los nexos básicos entre la razón y la afectividad, así como el valor metodológico del despliegue de una aprehensión que integre a ambas facultades humanas o por lo menos, que no las separe y, más aún, que no las oponga. La integración de estas capacidades humanas es un fortalecimiento de las posibilidades humanas y se debe aprovechar en el marco de la formación universitaria para que sea más óptima y la humanidad tenga profesionales formados de manera integral, que es una vía para contribuir a solucionar problemas actuales y futuros.

La formación universitaria para que sea verdaderamente valiosa tiene que corresponderse con las características y necesidades de la sociedad. Con esta afirmación, que es un principio de su funcionamiento, hoy se debe luchar contra el fraccionamiento y la separación arbitrarios y contra el reduccionismo. El desarrollo actual de la ciencia y las tecnologías evidencia la necesidad de transformar el pensamiento para, como recalca Edgar Morin, no huir de la complejidad de la vida, sino entenderla y asumirla, aprehender los nexos existentes (visibles y ocultos), establecer otros, y abrir los caminos a la integración.

\section{Conclusiones}

El espíritu integrador que sustenta y recorre el pensamiento de Edgar Morin tiene una base objetiva: la necesidad de transformar el modo de pensar de la humanidad para que se corresponda con las características de la sociedad actual, lo cual a su vez exige la rearticulación de todo cuanto a lo largo de los siglos fue separado, como los diversos saberes y las especialidades científicas y académicas. Para el pensador, la integración constituye un proceso de complementación, cuyo derrotero es el mejoramiento humano alcanzable en un marco histórico.

Existe una coherencia entre las sugerencias de Morian y las características de su pensamiento en cuanto a la articulación e integración, pues forman una malla interrelacionada, tanto en su manifestación, como en su espíritu.

La esencia integradora del pensamiento de Edgar Morin es valiosa para la formación universitaria, ante todo porque puede constituirse como sustento teórico para conservar la naturaleza universal de este nivel académico y acabar con la mentalidad que fracciona y reduce, que se deja sentir en no pocas concepciones y hechos, como la sobrevaloración del componente laboral y la división esquemática entre lo racional y lo afectivo. 
El carácter integrador de las ideas de Morin ofrece dos argumentos básicos para llevar adelante la gran faena reintegradora, uno es que el fraccionamiento tiene lugar no solo en la separación y aislamiento de características, propiedades, propósitos, sino también en la persistencia de la sobrevaloración de alguno de ellos; el otro es que para afianzar el carácter integrador consustancial a la formación universitaria hay que frenar en ella la tendencia a las sobrevaloraciones, como sucede en cuanto a lo estrictamente profesional, y, a su vez, es necesario atender con mayor vehemencia y de manera sistemática, el equilibrio entre lo racional y lo afectivo. La formación universitaria no ha de parcializarse a favor de ninguna de estas cualidades humanas.

\section{Bibliografía}

AGUILAR ASTORGA, Carlos Ricardo

2017 Crítica desde el pensamiento complejo a los métodos cuantitativos para el análisis educativo. El caso de los rendimientos educativos. Revista Educación y Humanismo, 19(33), 357-368. http://dx.doi.org/10.17081/eduhum.19.33.2649

ÁLVAREZ DEL VALLE, VIANEY, Lidia, PÉREZ MAYA, Coralia Juana \& LARA VILLANUEVA, Rosamary Selene

2019 Las tareas problematizadoras como propuesta para el desarrollo del pensamiento complejo. Revista Metropolitana de Ciencias Aplicadas, 2(2), 75-83. Recuperado de: https://bit.ly/306vonk

ÁLVAREZ NIETO, María Guadalupe

2017 El conocimiento del conocimiento: la obra de Edgar Morin y la problemática de la educación mexicana. Revista de investigación educativa de la REDIECH, 7(13), 6-20. Recuperado de: https://bit.ly/2z0knIV

BALLADARES BURGOS, Jorge Antonio, AVILÉS SALVADOR, Mauro Rodrigo \& PÉREZ NARVÁEZ, Hamilton Omar

2016 Del pensamiento complejo al pensamiento computacional: retos para la educación contemporánea. Sophia, Colección de Filosofía de la Educación, 21, 143-159. Recuperado de: https://bit.ly/3dypmzu

BARRANTES-ELIZONDO, Lena

2016 Educación emocional: El elemento perdido de la justicia social. Revista Electrónica Educare, 20(2), 4-11. http://dx.doi.org/10.15359/ree.20-2.24

BELLIDO MAINAR, José Ramón

2016 El pensamiento de Edgar Morin y su aplicación a la terapia ocupacional psicosocial. TOG, 13(24), 1-15. Recuperado de: https://bit.ly/30b1vlT

BERMÚDEZ-APONTE, José \& LASPALAS, Francisco

2017 El profesor universitario: integración entre lo personal y lo profesional. Teoría de la Educación. Revista Interuniversitaria, 29(2), 109-126. http://dx.doi. org/10.14201/teoredu292109126 
BISQUERRA ALZINA, Rafael

2005 La educación emocional en la formación del profesorado. Revista Interuniversitaria de Formación del Profesorado, 19(3), 95-114. Recuperado de: https://bit.ly/3058vRd

BOTTO, Marcelo Norberto

2018 Edgar Morin. La cultura de masas como objeto de análisis. Question, 1(60), 1-19. https://doi.org/10.24215/16696581e094

BROWER BELTRAMIN, Jorge

2014 Reflexiones en torno a la re-afirmación del sentido de la Universidad. Revista Internacional de Investigación en Ciencias Sociales, 10(2), 213-229. Recuperado de: https://bit.ly/36WgNfu

BUENO TORRENS, David \& FORÉS MIRAVALLE, Anna

20185 principios de la neuroeducación que la familia debería saber y poner en práctica. Revista Iberoamericana de Educación, 78(1). Recuperado de: https://bit.ly/3dBuuTO

CABRERA CUEVAS, Jessica \& DE LA HERRÁN GASCÓN, Agustín

2015 Creatividad, complejidad y formación: un enfoque transdisciplinar. Revista Complutense de Educación, 26(3), 505-526. http://dx.doi.org/10.5209/rev_ RCED.2015.v26.n3.43876

CALVO CEREIJO, María del Carmen

2019 Pensamiento complejo y transdisciplina. Sophia, Colección de Filosofía de la Educación, 26(1), 307-326. http://doi.org/10.17163/soph.n26.2019.09

CAMPERO, María Belén

2017 Un individuo-sujeto. El yo como una unidad compleja. Revista de Filosofía, 42(1), 135-151. http://dx.doi.org/10.5209/RESF.55453

CASTAÑEDA SERNA, Claudia María

2014 Competencia socio afectiva en el marco escolar colombiano. Escenarios, 12(2), 19-34. http://dx.doi.org/10.15665/esc.v12i2.312

CASTELLANOS, Ana Victoria

2016 El profesional universitario. En Tania Ortiz y Teresa Sanz, (Coord.), Visión pedagógica de la formación universitaria actual (pp.125-152). La Habana, Cuba: Editorial UH.

CIURANA, Emilio Roger \& REGALADO LOBO, Cecilia

2017 Reflexiones en torno a la relación entre pedagogía, currículo y pensamiento complejo. Revista del Centro de Investigación de la Universidad La Salle, 12(48), 9-30. http://dx.doi.org/10.26457/recein.v12i48.1508

CUERVO BALLESTEROS, Luis Esteban

2017 Formar para la participación democrática. Caminos de la educación para la paz. Reflexiones sobre la educación para la paz, condiciones legales y construcción de estrategias de formación de la participación ciudadana en la escuela. Uni-pluriversidad, 17(2), 39-46. Recuperado de: https://bit.ly/2Mn0cIm

CURIEL PEÓN, Laura

2018 Programa de formación docente en educación socioafectiva de profesores universitarios. (Tesis doctoral). Universidad de La Habana, Cuba.

CURIEL PEÓN, Laura, OJALVO MITRANY, Victoria \& CORTIZAS ENRÍQUEZ, Yinet

2018 La educación socioafectiva en el proceso de enseñanza aprendizaje. Revista Cubana de Educación Superior, (3), 80-92. Recuperado de: https://bit. ly/2Bs95xX 
CORONA FERNÁNDEZ, Javier

2019 Ontología y lenguaje: verdad y sentido en el umbral de las dos culturas. Sophia, Colección de Filosofía de la Educación, 27(2), 105-140. https://doi. org/10.17163/soph.n27.2019.03

DUARTE DÍAZ, Jenny Johanna \& VALBUENA USSA, Edgar Orlay

2014 Referentes de la formación de profesores en educación ambiental. Revisión de antecedentes 2000-20121. Uni-pluriversidad, 14(2), 27-36. Recuperado de: https://bit.ly/2yXjG30

ESCOBAR, Ricardo Antonio \& ESCOBAR, María Beatriz

2016 La relación entre el pensamiento complejo, la educación y la pedagogía. Administración y Desarrollo, 46 (1), 88-99. Recuperado de: https://bit. ly/2Bs9qkd

FERNÁNDEZ DOMÍNGUEZ, María Rosario, PALOMERO PESCADOR, José Emilio \& TERUEL MELERO, María del Pilar

2009 El desarrollo socioafectivo en la formación inicial de los maestros. REIFOP, 12(1), 33-50. Recuperado de: https://bit.ly/3ctzDM7

FERRADA-SULLIVAN, Jorge

2017 Reflexiones preliminares para pensar la formación de formadores en la universidad moderna: Nuevas miradas y nuevos diálogos desde la complejidad. Revista Electrónica Educare, 21(2), 1-17. http://orcid.org/0000-0001-5966-6796

FRAGOSO-LUZURIAGA, Rocío

2015 Inteligencia emocional y competencias emocionales en educación superior, ¿un mismo concepto? Revista Iberoamericana de Educación Superior, 6(16), 110-125. Recuperado de: https://bit.ly/3gSQTO6

GOICOECHEA GAONA, María Ángeles \& FERNÁNDEZ GUERRERO, Olaya

2014 Filosofía y educación afectiva en Amor y pedagogía, de Unamuno. Teoría de la Educación. Revista Interuniversitaria, 26(1), 41-58. http://dx.doi. org/10.14201/teoredu20142614158

GONZÁLEZ RIVERO, Berta Margarita

2016 La categoría formación. En Tania Ortiz y Teresa Sanz (Coord.), Visión pedagógica de la formación universitaria actual (pp.153-169). La Habana, Cuba: Editorial UH.

2019 Retos de la formación ciudadana para la educación superior. Universidad y Sociedad, 11(4), 341-349. Recuperado de: https://bit.ly/301oOyp

GONZÁLEZ VELASCO, Juan Miguel

2017 Teoría educativa transcompleja. Barranquilla: Universidad Autónoma del Caribe.

2019 El aula mente social como potencial creativo en la educación: enfoque desde el pensamiento complejo. Educación Superior, 6(1), 34-38. Recuperado de: https://bit.ly/3gPybqG

GUADARRAMA GONZÁLEZ, Pablo

2018 Para qué sirve la epistemología a un investigador y a un profesor. Bogotá: Cooperativa Editorial Magisterio.

HERNÁNDEZ FERNÁNDEZ, Herminia \& FIGUEROLA DOMENECH, María Carla

2016 Miradas pedagógicas a la formación universitaria en documentos políticoacadémicos. Reflexiones sobre la universidad en Cuba. En Tania Ortiz y Teresa Sanz (Coord.), Visión pedagógica de la formación universitaria actual (pp.17-41). La Habana, Cuba: Editorial UH. 
HUERTAS DÍAZ, Omar

2015 Incidencia de la educación desde un paradigma complejo en la formación de ciudadanos Ciudad paz-ando, 8(2), 125-138. http://dx.doi.org/10.14483/ udistrital.jour.cpaz.2015.2.a07

LEÓN CASTILLO, Yusdiel, REINÉ HERRERA, Yaumary \& CHARBONELL MARTEL, Miguel Enrique

2019 Una mirada a la formación de profesionales universitarios que demanda el siglo XXI en Cuba. Revista Cubana de Educación Superior, 38(1), e10. Recuperado de: https://bit.ly/301EYaZ

MALDONADO, Carlos Eduardo

2017 Educación compleja: Indisciplinar la sociedad. Revista Educación y Humanismo, 19(33), 234-252. http://dx.doi.org/10.17081/eduhum. 19.33.2642

MALDONADO-TORRES, Sonia, ARAUJO, Victoria \& RONDÓN, Oneirys

2018 Enseñar como un 'acto de amor' con métodos de enseñanza-aprendizaje no tradicionales en los entornos virtuales. Revista Electrónica Educare, 22(3), 1-12. http://dx.doi.org/10.15359/ree.22-3.18

MARINA, José Antonio

2005 Precisiones sobre la Educación Emocional. Revista Interuniversitaria de Formación del Profesorado, 19(3), 27-43. Recuperado de: https://bit.ly/2AxpPDA

MARTÍNEZ PRIEGO, Consuelo

2015 Urdimbre afectiva y educación. Aproximación a las ideas pedagógicas de Juan Rof Carballo. Estudios sobre Educación, 28, 139-154. http://dx.doi. org/10.15581/004.28.139-154

MARTÍNEZ-LÓPEZ, Juan José

2017 Aportes teóricos para una reconsideración de identidades y formas sociopolíticas: neurociencia, evolución y complejidad Revista Internacional de Pensamiento Político, 12, 483-506. Recuperado de: https://bit.ly/3cutwHm

MORA, Francisco

2015 Neuroeducación. Solo se puede aprender aquello que se ama. Madrid: Alianza Editorial.

MORIN, Edgar

1992 El Método. Las ideas, t. IV. Madrid: Ediciones Cátedra.

1999 El Método. El conocimiento del conocimiento, t. III. Madrid: Ediciones Cátedra.

1999a Los siete saberes necesarios para la educación del futuro. París: UNESCO.

2001 El Método. La naturaleza de la Naturaleza, t. 1. Madrid: Ediciones Cátedra.

2002 El Método. La vida de la vida, t. II. Madrid: Ediciones Cátedra.

2003 El Método. La humanidad de la humanidad. La identidad humana, t. V. Madrid: Ediciones Cátedra.

2006 El Método. Ética, t. VI. Madrid: Ediciones Cátedra.

NAVIA ANTEZANA, Cecilia \& HIRSCH ADLER, Ana

2015 Ética profesional en estudiantes de posgrado en dos universidades mexicanas. Revista Electrónica de Investigación Educativa, 17(1), 100-115. Recuperado de: https://bit.ly/2U9MWuZ

OJALVO MITRANY, Victoria \& CURIEL PEÓN, Laura

2018 La tradición humanista de la educación cubana: premisa para la formación docente en educación socioafectiva. Atenas, 3(43), 115-128. Recuperado de: https://bit.ly/2XWFJiW 
PACHECO GONZÁLEZ, María Caridad \& PUPO PUPO, Rigoberto

2017 José Martí, la educación como formación humana. La Habana: Centro de Estudios Martianos.

PÉREZ GUZMÁN, Jesús

2018 La formación de maestros para la enseñanza del lenguaje como práctica social. Uni-pluriversidad, 18(1), 36-46. http://dx.doi.org/10.17533/udea.unipluri.18.1.04

PICAZO, David, CONTRERAS, Claudia Patricia, PÉREZ-PIÑÓN, María Teresa \& PÉREZ-PIÑÓN, Dagoberto

2018 Competencias y pensamiento complejo en estudiantes de programas de posgrado. Tecnociencia Chihuahua, 12(1), 1-11. Recuperado de: https://bit. ly/3gPC1QB

RAMOS SERPA, Gerardo

2006 La formación humanística como componente de la formación integral del profesor universitario. Revista Educação em Questão, 27(13), 7-27. Recuperado de: https://bit.ly/2zY814A

RESTREPO ZAPATA, Diego

2017 El constructivismo, la metacognición y el pensamiento complejo como estrategia tripartita para el desarrollo de la gestión del conocimiento y las competencias laborales. Certiuni Journal, (3), 47-65. Recuperado de: https:// bit.ly/2MqVqt

RODRÍGUEZ TORRES, Ángel Freddy

2016 El pensamiento complejo y los desafíos de la educación física. Revista Enlace Universitario, 1, 25-32. Recuperado de: https://bit.ly/2Y4bnv4

RODRÍGUEZ, Milagros Elena

2017 Currículum, educación y cultura en la formación docente del siglo xxi desde la complejidad. Revista Educación y Humanismo, 19(33), 425-440. http:// dx.doi.org/10.17081/eduhum.19.33.2654

RUBIO TERRADO, Pascual

2018 Aplicación de las teorías de la complejidad a la comprensión del territorio. Estudios Geográficos, 89(284), 237-265. https://doi.org/10.3989/estgeogr.201810

RUIZ LARA, Beatriz Cecilia \& TORRES SOLER, Luis Carlos

2016 Pensamiento complejo y creatividad. Revista Ontare, 4(2), 7-26. https://doi. org/10.21158/23823399.v4.n2.2016.1625.

VALLEJOS, Rosse Marie \& COLL, Gretel

2017 Filosofía con niños, niñas y jóvenes: una experiencia en el desarrollo del pensamiento complejo y valores humanistas laicos en una escuela pública. Paideia, 61, 101-117. Revuperado de: https://bit.ly/2zYchB8

Vallejo-Gómez, Nelson

2017 Entramar conocimientos y saberes necesarios para la educación del futuro (sobre las propuestas pedagógicas de Edgar Morin). Gazeta de Antropología, 33(2), 20-34. Recuperado de: https://bit.ly/2zYaX15

VÁZQUEZ ALONSO, Ángel

2014 Enseñanza, Aprendizaje y Evaluación en la Formación de Docentes en Educación CTS en el contexto del siglo XXI. Uni-pluriversidad, 14(2), 37-49. Recuperado de: https://bit.ly/3gX9fhl 
VÁZQUEZ ANTONIO, José Manuel, HERNÁNDEZ MOSQUEDA, José Silvano, VÁZQUEZ ANTONIO, Jennifer, JUÁREZ HERNÁNDEZ, Luis Gibran \& GUZMÁN CALDERÓN, Clara Eugenia

2017 El trabajo colaborativo y la socioformación: un camino hacia el conocimiento complejo. Revista Educación y Humanismo, 19(33), 334-356. http:// dx.doi.org/10.17081/eduhum.19.33.2648

VEGA CÁRDENAS, Yenny

2016 La innovación: el reto de formar profesionales aptos para enfrentarse a la incertidumbre. Blanco y Negro, 7(1), 6-20. Recuperado de: https://bit. ly/3eSUbiV

VELÁZQUEZ JIMÉNEZ, Claudia Marcela

2016 La formación en investigación de los docentes universitarios. Estudio de caso en una Institución de Educación Superior Colombiana. Uni-pluriversidad, 16(1), 15-25. Recuperado de: https://bit.ly/2z0NnAh

VELDUCEA VELDUCEA, Wilberth, MARÍN URIBE, Rigoberto \& SOTO VALENZUELA, María Concepción

2019 Estrategias de intervención y pensamiento complejo en la formación universitaria: revisión sistemática. Revista Publicando, 6(20), 5-11. Recuperado de: https://bit.ly/2zP9aLV

VENEGAS RENAULD, María Eugenia

2004 El Renacimiento: un contexto para el surgimiento del concepto pedagógico 'formación'. Educación, 28(1), 27-37. Recuperado de: https://bit.ly/2YlJMqh

2004a El concepto pedagógico formación en el universo semántico de la educación. Educación, 28(2), 13-28. Recuperado de: https://bit.ly/2U1UpMz

VIGURI AXPE, Miguel Ramón

2019 Ciencias de la complejidad versus pensamiento complejo. Claves para una lectura crítica del concepto de cientificidad en Carlos Reynoso. Pensamiento, 75(283), 87-106. https://doi.org/10.14422/pen.v75.i283.y2019.004

ZABALZA, Miguel

2011 Formación del profesorado universitario: mejorar a los docentes para mejorar la docencia. Educação, Santa Maria, 36(3), 397-424. Recuperado de: https://bit.ly/3coXsEU

Fecha de recepción de documento: 5 de diciembre de 2019

Fecha de revisión de documento: 5 de enero de 2020

Fecha de aprobación de documento: 5 de mayo de 2020

Fecha de publicación de documento: 15 de julio de 2020 